\title{
Correction to: Black spot infection in juvenile steelhead trout increases with stream temperature in northern California
}

\author{
Cody J. Schaaf • Suzanne J. Kelson • \\ Sébastien C. Nusslé • Stephanie M. Carlson
}

Published online: 5 April 2018

(C) Springer Science+Business Media B.V., part of Springer Nature 2018

\section{Correction to: Environ Biol Fish \\ https://doi.org/10.1007/s10641-017- 0599-9}

The original version of this article contained two mistakes, which we detail here. First, the percent infected data for sites 6 and 7 were inadvertently switched in the published version of Table 1. The corrected version of Table 1 appears below. Second, there were four errors in the temperature data used in analyses and published in the article. The corrected changes to analyses that used these data are underlined in the following text and corrected versions of Figs. 4 and 5 (which relied on these data) are included below.

Third paragraph under Results:

The mixed models of the seven mainstem sampling sites revealed that both temperature and sample date are important covariates in determining the proportion of infected steelhead at each site. Temperature was significant in the first (i.e., temperature [fixed] and site [random]) model $(\mathrm{z}=$ 6.91, $p<0.01, \mathrm{AIC}=\underline{182.4}$. . Sample date was significant in the second (i.e., sample date [fixed] and site $[$ random] $)$ model $(\mathrm{z}=9.88, p<0.01, \mathrm{AIC}=$ 124.6). In the final model (temperature [fixed], sample date [fixed], and site), both fixed effects were statistically significant, and this model was associated the lowest AIC value (temperature: $\mathrm{z}=$ 4.71, $p<0.01$, sample date: $\mathrm{z}=\underline{7.32} p<0.01$, $\overline{\mathrm{AIC}}=\underline{94.4}$.

The online version of the original article can be found at https://doi.org/10.1007/s10641-017-0599-9

C. J. Schaaf · S. J. Kelson · S. C. Nusslé •

S. M. Carlson $(\bowtie)$

Department of Environmental Science, Policy, and Management, University of California, 130 Mulford Hall \#3114, Berkeley, CA 94720-3114, USA

e-mail: smcarlson@berkeley.edu 
Table 1 Summary of the 7-day average daily maximum temperature $\left(\mathrm{ADM},{ }^{\circ} \mathrm{C}\right)$ and black spot infection rates $(\%)$ in young of the year steelhead trout at each site and each sampling event $(\mathrm{n}=$ sample size). Sites are listed in order from upstream (Site 1) to downstream (Site 7)

\begin{tabular}{lllrl}
\hline Site & Date & ADM & \% Infected & $\mathrm{n}$ \\
\hline 1 & $6 / 5 / 2014$ & 20.9 & 0.0 & 18 \\
1 & $6 / 30 / 2014$ & 20.5 & 8.6 & 35 \\
1 & $8 / 21 / 2014$ & 21.5 & 33.3 & 18 \\
2 & $6 / 18 / 2014$ & $\underline{19.5}$ & 0.0 & 44 \\
2 & $7 / 7 / 2014$ & 23.0 & 7.6 & 66 \\
2 & $8 / 21 / 2014$ & 21.7 & 36.4 & 11 \\
3 & $6 / 18 / 2014$ & $\underline{21.3}$ & 0.0 & 28 \\
3 & $7 / 7 / 2014$ & 25.2 & 52.0 & 25 \\
3 & $8 / 21 / 2014$ & 22.4 & 100.0 & 19 \\
4 & $6 / 18 / 2014$ & 21.5 & 0.0 & 45 \\
4 & $6 / 30 / 2014$ & 23.2 & 11.5 & 26 \\
4 & $8 / 21 / 2014$ & $\mathrm{NA}$ & 92.9 & 28 \\
5 & $6 / 23 / 2014$ & 21.7 & 6.3 & 16 \\
5 & $7 / 13 / 2014$ & 24.7 & 100.0 & 22 \\
5 & $8 / 21 / 2014$ & 24.7 & 100.0 & 42 \\
6 & $\frac{6 / 30 / 2014}{7 / 13 / 2014}$ & $\underline{25.1}$ & $\underline{96.2}$ & $\underline{26}$ \\
6 & $8 / 21 / 2014$ & 24.8 & $\underline{87.0}$ & $\underline{100.0}$ \\
6 & $\frac{6 / 25 / 2014}{7 / 13 / 2014}$ & 23.1 & $\underline{76.5}$ & $\underline{100.0}$ \\
7 & $8 / 21 / 2014$ & 23.4 & $\underline{100.0}$ & $\underline{13}$ \\
7 & & & & \\
7 & & 23.7 & \\
\hline
\end{tabular}

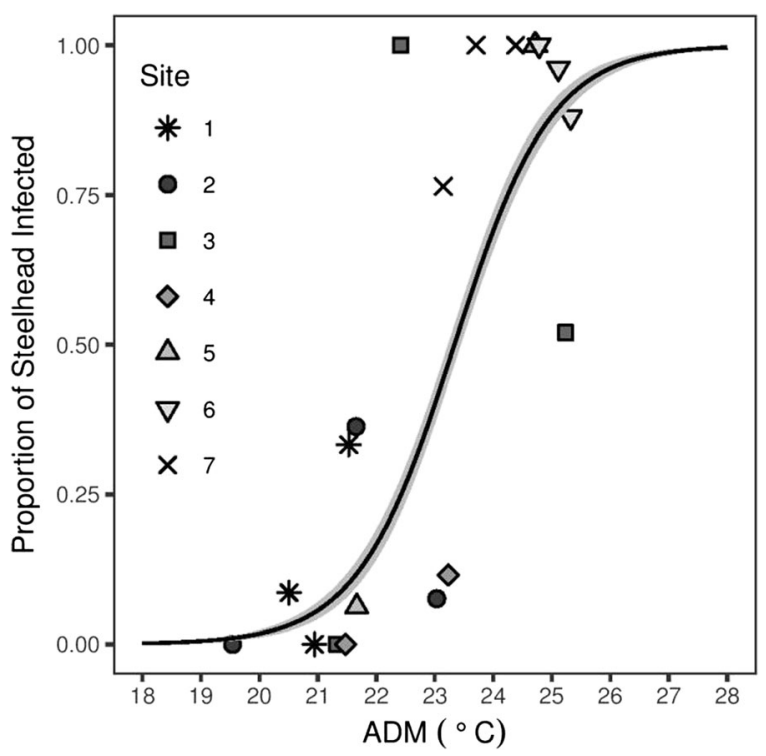

Fig. 4 Relationship between trout infection rates and average daily maximum $(\mathrm{ADM})$ water temperature calculated over 7-day windows

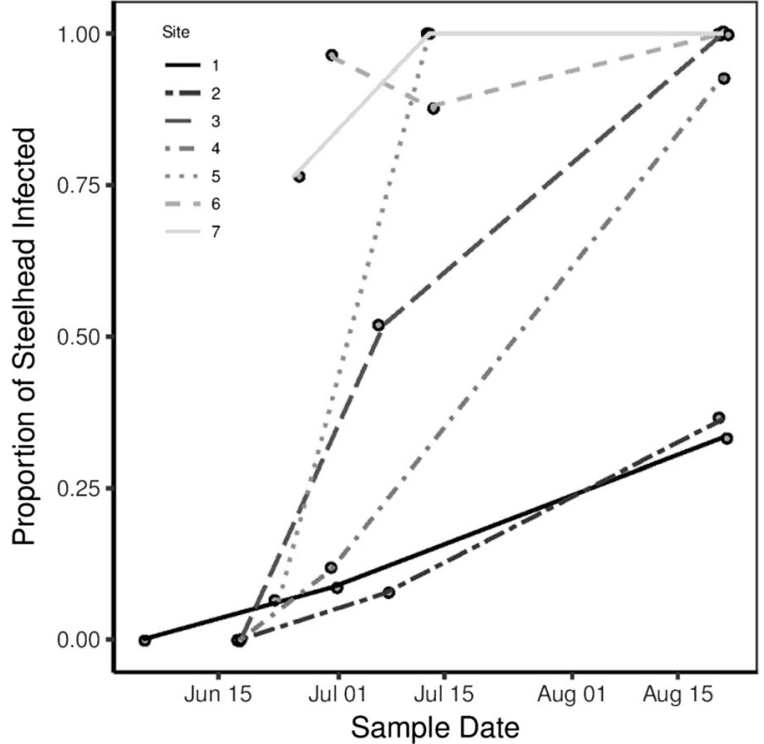

Fig. 5 Temporal trend in trout infection rates at each site over the study period, highlighting differences among early, middle, and late sampling events at each site. Refer to Fig. 1 for the location of sites 1-7 along the mainstem South Fork Eel River 